\title{
Fasting metabolism and thermoregulatory competence of the star-nosed mole, Condylura cristata (Talpidae: Condylurinae)
}

\author{
Kevin L. Campbell *, Ian W. McIntyre, Robert A. MacArthur \\ Department of Zoology, University of Manitoba, R3T 2N2, Winnipeg, Canada
}

Received 27 December 1998; received in revised form 10 March 1999; accepted 7 April 1999

\begin{abstract}
Metabolic and body temperature $\left(T_{\mathrm{b}}\right)$ responses of star-nosed moles (Condylura cristata) exposed to air temperatures ranging from 0 to $33^{\circ} \mathrm{C}$ were investigated. The thermoneutral zone of this semi-aquatic mole extended from 24.5 to $33^{\circ} \mathrm{C}$, over which its basal rate of metabolism averaged $2.25 \mathrm{ml} \mathrm{O}_{2} \mathrm{~g}^{-1} \mathrm{~h}^{-1}\left(45.16 \mathrm{~J} \mathrm{~g}^{-1} \mathrm{~h}^{-1}\right)$. This rate of metabolism is higher than predicted for terrestrial forms, and substantially higher than for other moles examined to date. Minimum thermal conductance was nearly identical to that predicted for similar-sized eutherians and may represent a compromise between the need to dissipate heat while digging and foraging in subterranean burrows, and the need to conserve heat and avoid hypothermia during exposure to cold. $C$. cristata precisely regulated $T_{\mathrm{b}}$ (mean $\pm \mathrm{SE}=37.7 \pm 0.05^{\circ} \mathrm{C}$ ) over the entire range of test temperatures. Over three separate 24-h periods, $T_{\mathrm{b}}$ of a radio-implanted mole varied from 36.6 to $38.8^{\circ} \mathrm{C}$, and generally tracked level of activity. No obvious circadian variation in $T_{\mathrm{b}}$ and activity was apparent, although cyclic $2-4 \mathrm{~h}$ intervals of activity punctuated by periods of inactivity lasting $3-5 \mathrm{~h}$ were routinely observed. We suggest that the elevated basal metabolic rate and relatively high $T_{\mathrm{b}}$ of star-nosed moles may reflect the semi-aquatic habits of this unique talpid. (C) 1999 Elsevier Science Inc. All rights reserved.
\end{abstract}

Keywords: Condylura; Star-nosed mole; Metabolism; Thermal biology; Body temperature; Conductance; Insectivore; Activity pattern

\section{Introduction}

The star-nosed mole (Condylura cristata), distinguished by its strange and conspicuous [22] fleshy-appendage proboscis, is the only member of the subfamily Condylurinae [29]. Unique among North American moles for its semi-aquatic habit and predilection for moist soils bordering on streams and lakes, the starnosed mole is an adept burrower and excellent swimmer $[13,14]$. Direct observations of star-nosed moles indicate an active lifestyle, prompting speculation of a voracious appetite and 'high metabolism' $[4,5,13,31,33]$. Yet few data exist on even the most basic energetics of this curious invertebrativore. Indeed, information of this nature is limited to metabolic measurements obtained from two immature moles held at $27-28^{\circ} \mathrm{C}$ [37] and

\footnotetext{
* Corresponding author. Present address: Department of Zoology, University of British Columbia, 6270 University Boulevard, Vancouver, British Columbia, Canada; tel.: + 1-604-822-6759; fax: + 1-604822-2416.

E-mail address: campbelk@zoology.ubc.ca (K.L. Campbell)
}

from a single, restless 60-g specimen [28] that presumably was held at a similar air temperature.

The star-nosed mole ranges considerably farther north than any other North American talpid [29]. In fact, these animals have been observed tunneling through snow and even diving under ice during winter $[13,26,33]$. Moreover, analysis of stomach contents indicate that aquatic invertebrates are taken year round $[13,30]$, and reportedly occur in the diet most frequently during winter. These observations imply a high level of thermoregulatory competence in this species, perhaps coupled with an elevated basal metabolic rate (BMR). Non-hibernating small mammals inhabiting cold environments, including semi-aquatic forms, often exhibit higher BMRs and lower heat transfer coefficients than predicted from allometry $[9,18,34]$. Though controversial, it has been speculated that these features are consistent with the high rates of thermogenesis and risks of hypothermia posed by chronic exposure to cold $[8,32]$.

Like aquatic foraging, burrowing is considered one of the most energetically demanding activities engaged 
in by mammals [16,35]. However, the confined burrow environment impedes heat dissipation [19] and the inherently low gas permeability of soil may reduce oxygen availability and increase the risk of respiratory acidosis to fossorial mammals [2]. Consequently, an elevated BMR and reduced minimal thermal conductance $\left(C_{\mathrm{m}}\right)$ would not only increase the risk of hyperthermia in burrowing mammals $[6,16,20,21]$, but may also aggravate disturbances of respiratory gases in burrow micro-environments [2]. Clearly, physiological phenotypes suited for subterranean life may be at variance with those compatible with a semi-aquatic existence. While much has been learned of the metabolic organization and thermal biology of fossorial and semiaquatic rodents $[6,9,18,20,21]$, data for comparable Insectivora [34] are scarce. The star-nosed mole manifests a clear propensity for both subterranean and aquatic environments and thus affords an ideal model for such investigation.

This paper is the first to report on the metabolic rate, thermal conductance and thermoregulatory performance of wild-caught star-nosed moles exposed to a range of ambient temperatures likely to be encountered by these animals in nature. Additional information on the daily activity and body temperature $\left(T_{\mathrm{b}}\right)$ patterns of these unusual invertebrativores also are presented.

\section{Materials and methods}

\subsection{Study animals}

A total of 12 star-nosed moles of both sexes were livetrapped $2 \mathrm{~km}$ north of Piney, Manitoba $\left(49^{\circ} 06^{\prime} \mathrm{N}\right.$, $95^{\circ} 59^{\prime}$ W), during June 1997/1998 and transported to the Animal Holding Facility, University of Manitoba. Animals were held at $20 \pm 1{ }^{\circ} \mathrm{C}$ with a 12:12 light:dark photoperiod, and housed individually in rectangular plywood chambers $(88 \times 50 \times 60 \mathrm{~cm})$ filled with $45 \mathrm{~cm}$ of sterilized soil (ca. $60 \%$ peat moss, $20 \%$ sand and $20 \%$ potting soil mixture). The soil was moistened daily and chambers were covered with fine mesh netting, providing moles with dim, humid conditions approximating those of their natural habitat. Each container was attached via a length of ABS tubing (internal diameter, $4 \mathrm{~cm}$ ) to a 40-1 glass aquarium filled with $25 \mathrm{~cm}$ of water. Swimming tanks were covered with Plexiglas and fitted with removable ramps to allow easy access of moles to and from the water. Animals were maintained on a mixed ration of pork brain, beef heart, liver, kidney, hamburger, and canned cat food enriched with multivitamin and calcium supplements. Commercially purchased nightcrawlers (Lumbricus spp.), leeches (Nephelopsis obscura) and mealworms (Tenebrio molitor) also were provided daily. While in captivity, moles were cared for in accordance with the principles and guidelines of the Canadian Council on Animal Care and under the authorization of a University-approved animal research protocol.

\subsection{Metabolic measurements}

Resting rates of oxygen consumption $\left(\dot{V}_{\mathrm{O}_{2}}\right)$ and carbon dioxide production $\left(\dot{V}_{\mathrm{CO}_{2}}\right)$ were measured using a negative pressure, open-flow respirometry system. Animals were fasted for $4-8 \mathrm{~h}$, weighed to the nearest 0.01 $\mathrm{g}$, and transferred to a modified $0.95-1$ paint can fitted with inlet and outlet ports, that was installed in a temperature-controlled cabinet. The interior of the metabolic chamber was painted flat black to reduce radiative heat transfer and was furnished with 3-4 mm of dry, sterilized soil (see above). This latter provision increased the frequency and duration of stable metabolic readings from test animals. Dry $\mathrm{CO}_{2}$-free room air was drawn through the chamber at a rate of $900 \pm 10 \mathrm{ml} \mathrm{min}^{-1}$ (TR-SS1 gas analysis sub-sampler; Sable Systems Inc., Henderson, NV). A portion of the

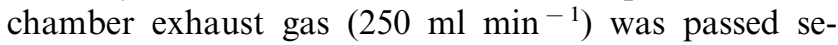
quentially through a Drierite column, a Beckman LB-2 carbon dioxide analyzer, soda lime and Drierite trains, and an Applied Electrochemistry S3-A oxygen analyzer. Following a 30-45-min settling period, chamber ambient temperature $\left(T_{\mathrm{a}}\right)$, air flow rate, and fractional $\mathrm{CO}_{2}$ and $\mathrm{O}_{2}$ contents of chamber exhaust gas were recorded every $5 \mathrm{~s}$ for a period of $1-3 \mathrm{~h}$, using Datacan $\mathrm{V}$ data acquisition software (Sable Systems Inc.). During metabolic trials conducted in 1998, animal activity was recorded at 5-s intervals with a MAD-1 motion/activity detector (Sable Systems Inc.). At test temperatures $>30^{\circ} \mathrm{C}$ (conducted in 1998 only) motor activity was virtually non-existent. Consequently, metabolic trials above $30^{\circ} \mathrm{C}$ were shortened to $\leq 1 \mathrm{~h}$ to reduce the risk of hyperthermia.

Resting $\dot{V}_{\mathrm{O}_{2}}$ was calculated as the average of the three lowest steady-state values, each lasting at least 3-5 min. Use of the motion/activity detector aided identification of resting periods in the 1998 metabolic trials. $\dot{V}_{\mathrm{CO}_{2}}\left(\mathrm{ml} \mathrm{h}^{-1}\right)$ was calculated by multiplying the fractional $\mathrm{CO}_{2}$ content of excurrent gas by chamber flow rate, and $V_{\mathrm{O}_{2}}$ determined as:

$$
\begin{aligned}
& \dot{V}_{\mathrm{O}_{2}}\left(\mathrm{ml} \mathrm{g}^{-1} \mathrm{~h}^{-1}\right) \\
& =\left[\left(\dot{V}_{\mathrm{e}}-\dot{V}_{\mathrm{CO}_{2}}\right) \times\left(\mathrm{FiO}_{2}-\mathrm{FeO}_{2}\right) /\left(1-\mathrm{FiO}_{2}\right)\right] / \text { body mass }
\end{aligned}
$$

where $\dot{V}_{e}$ is the flow rate $\left(\mathrm{ml} \mathrm{h}^{-1}\right)$ of dry excurrent gas and $\mathrm{FiO}_{2}$ and $\mathrm{FeO}_{2}$ are the fractional $\mathrm{O}_{2}$ contents of inlet and outlet air streams, respectively. Body mass (g) represents the average value for each trial.

To estimate the rate of heat exchange between the body and environment, coefficients of whole-body thermal conductance were calculated as [22]: conductance $=\dot{V}_{\mathrm{O}_{2}} /\left(T_{\mathrm{b}}-T_{\mathrm{a}}\right)$. 
We used a continuous two-phase regression model [27] to statistically calculate the lower critical temperature from metabolic data, and to derive the inflection point in the relationship of thermal conductance to $T_{\mathrm{a}}$ [3].

\subsection{Body temperature}

Initial attempts to record rectal temperatures were abandoned, owing to difficulties encountered in restraining these remarkably agile animals. We subsequently discovered that moles were easily restrained if provided access to a blind-ending, 3-cm diameter tunnel cut in a foam block. Immediately following metabolic testing, moles were allowed access to the tunnel and $T_{\mathrm{b}}$ determined with a copper-constantan thermocouple lubricated with mineral oil and inserted $1.5-2.0 \mathrm{~cm}$ into the rectum. The temperature probe was connected to a model BAT-12 thermocouple thermometer.

A limited number of abdominal $T_{\mathrm{b}}$ recordings were obtained from a single mole implanted with a 1.3-g model $\mathrm{X}-\mathrm{M}$ transmitter (Mini-Mitter Inc., Sunriver, OR). Transmitter calibration and implantation procedures are described elsewhere $[10,19]$. Star-nosed moles are highly prone to anesthesia-induced mortality, [1] and this study, and we found it best to anesthetize each mole in stages, as recommended by Catania (personal communication). Briefly, the animal was weighed to the nearest $0.01 \mathrm{~g}$, allowed access to the foam tunnel, and injected with Ketamine hydrochloride (ca. $35 \mathrm{mg} \mathrm{kg} \mathrm{kg}^{-1}$ i.p.). Within 5-10 $\mathrm{min}$, a second intraperitoneal injection (ca. $25 \mathrm{mg} \mathrm{kg}^{-1}$ ) was administered to establish a deep plane of anesthesia. Additional small doses (5-10 $\mathrm{mg} \mathrm{kg}{ }^{-1}$ ) were given as needed to maintain a surgical plane of anesthesia (Catania, in litt.). The sterilized transmitter was implanted into the abdominal cavity and the midline abdominal incision promptly closed. Metabolic measurements were initiated 1 week following surgery.

\subsection{Daily activity and $T_{b}$ patterns}

Three 24-h activity and $T_{\mathrm{b}}$ recordings were obtained from the single radio-implanted mole. The animal was housed in a 38-1 plastic container placed on the MAD-1 motion/activity detector. The container was furnished with a screen cover, $8 \mathrm{~cm}$ of soil, a small nest box, and a water dish. $T_{\mathrm{b}}$ was recorded at 10 -min intervals on analog tape using an automated recording system similar to that described by Dyck and MacArthur [10]. Activity was monitored at 15 -s intervals for the duration of the trial. Several additional 24-48-h activity recordings were obtained from two non-instrumented moles. For all trials, moles were held at $20 \pm 1^{\circ} \mathrm{C}$ with a 12:12 light:dark photoperiod. Food and water were provided ad libitum.

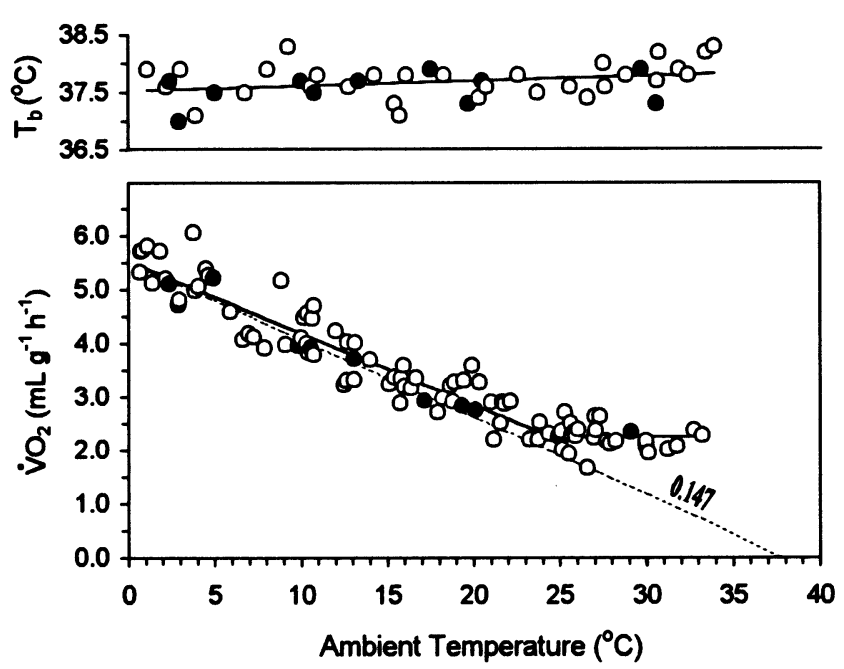

Fig. 1. The relationship of body temperature $\left(T_{\mathrm{b}}\right)$ and resting metabolic rate to air temperature in 12 fasted star-nosed moles, Condylura cristata. For $\dot{V}_{\mathrm{O}_{2}}$ data, the solid line was fitted using a continuous two-phase linear regression model [27]. The dashed regression line was derived by forcing the regression of $\dot{V}_{\mathrm{O}_{2}}$ on $T_{\mathrm{a}}$ to intersect the abscissa at mean $T_{\mathrm{b}}\left(37.7^{\circ} \mathrm{C}\right)$. The slope of this regression $\left(0.147 \mathrm{ml} \mathrm{g}^{-1} \mathrm{~h}^{-10} \mathrm{C}^{-1} \mathrm{O}_{2}\right)$ represents the minimal thermal conductance below thermoneutrality [22]. (๑) $\dot{V}_{\mathrm{O}_{2}}$ and telemetered $T_{\mathrm{b}}$ recordings for a single radio-implanted mole (see text).

\section{Results}

Based on the relationship between resting metabolic rate and $T_{\mathrm{a}}$ of fasted animals (Fig. 1), the lower critical temperature of the star-nosed mole was calculated to be $24.5^{\circ} \mathrm{C}$. This is reasonably close to the inflection point $\left(25.4^{\circ} \mathrm{C}\right)$ derived for the relationship between wholebody thermal conductance and $T_{\mathrm{a}}$ (Fig. 2). Although an upper critical temperature could not be clearly delineated, $T_{\mathrm{b}}, \dot{V}_{\mathrm{O}_{2}}$ and thermal conductance all increased slightly at $T_{\mathrm{a}}=33^{\circ} \mathrm{C}$ (Figs. 1 and 2), suggesting that

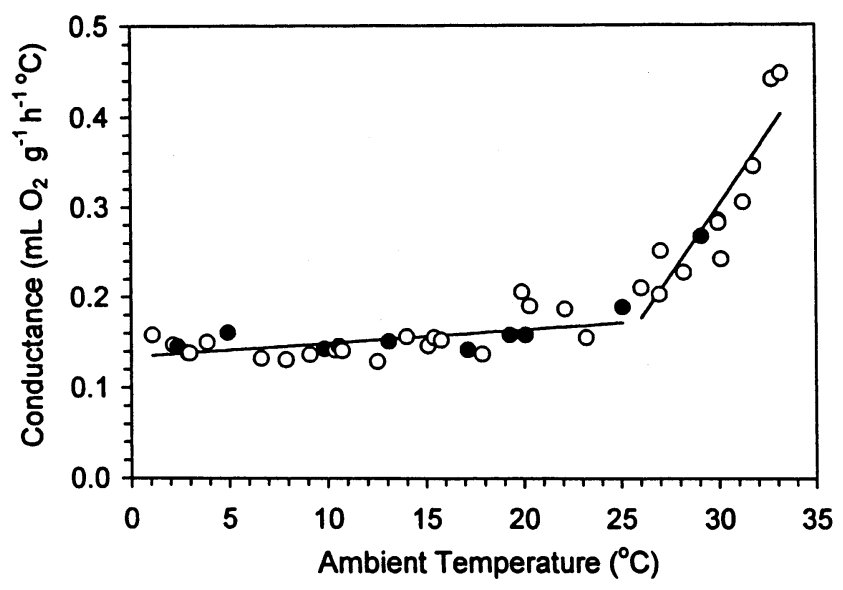

Fig. 2. Whole-body thermal conductance of fasted star-nosed moles in relation to air temperature. Regression lines were fitted using a continuous two-phase, straight-line regression model [27]. Closed circles denote values obtained from the radio-implanted mole (see text). 


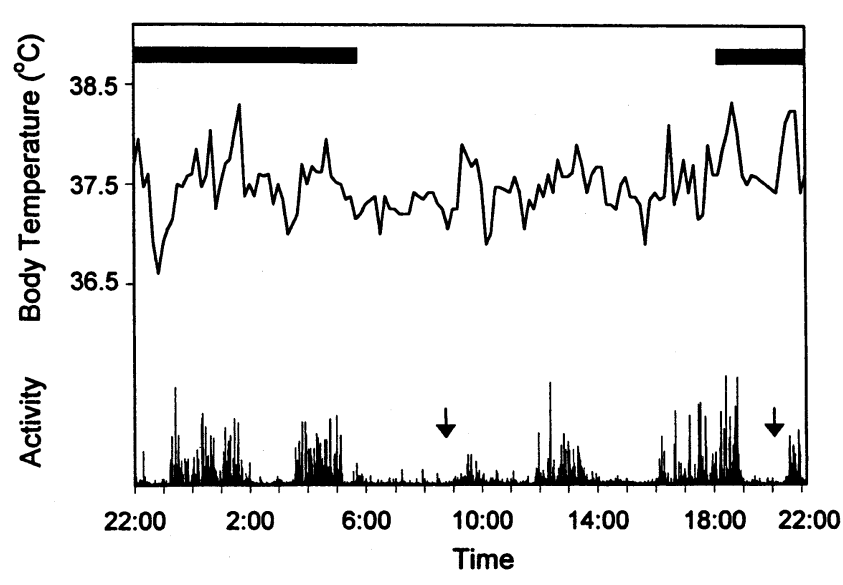

Fig. 3. Daily variation in telemetered abdominal temperature and motor activity of a radio-implanted star-nosed mole held at an air temperature of $20^{\circ} \mathrm{C}$. Amplitude of the activity trace denotes relative level of movement detected by an activity/motion sensor (see text for details). The solid bars indicate hours of darkness. Arrows indicate times fresh food and water were placed in the animal chamber.

this $T_{\mathrm{a}}$ was close to the upper limit of thermoneutrality. Based on all measurements above $24.5^{\circ} \mathrm{C}(n=25)$, the BMR $( \pm \mathrm{SE})$ of $C$. cristata was estimated to be $2.25 \pm$ $0.05 \mathrm{ml} \mathrm{O}_{2} \mathrm{~g}^{-1} \mathrm{~h}^{-1}$, or $45.16 \mathrm{~J} \mathrm{~g}^{-1} \mathrm{~h}^{-1}$. Assuming an average body mass of $49.0 \mathrm{~g}$, this value is $199.3 \%$ that predicted for a similar-sized eutherian, $\dot{V}_{\mathrm{O}_{2}}=3.45$ Mass $^{-0.287}$ [23]. Body temperature was closely regulated over the entire range of test temperatures (Fig. 1), averaging $37.7 \pm 0.05^{\circ} \mathrm{C}(n=42)$. Below thermoneutrality, $\dot{V}_{\mathrm{O}_{2}} \mathrm{v}$ increased as a linear function of air temperature: $\dot{V}_{\mathrm{O}_{2}}=5.534-0.134 T_{\mathrm{a}}$ (slope significantly different from zero, $\left.P<0.0001, n=71, r^{2}=0.88\right)$. The $C_{\mathrm{m}}$ derived by forcing the least-squares regression of $\dot{V}_{\mathrm{O}_{2}}$ on $T_{\mathrm{a}}$ to intersect the abscissa at $37.7^{\circ} \mathrm{C}$ [22] was 0.147 $\mathrm{ml} \mathrm{O}_{2} \mathrm{~g}^{-1} \mathrm{~h}^{-10} \mathrm{C}^{-1}$ (Fig. 1), whereas that obtained by averaging all values of conductance below thermoneutrality (Fig. 2) was $0.151 \mathrm{ml} \mathrm{O}_{2} \mathrm{~g}^{-1} \mathrm{~h}^{-10} \mathrm{C}^{-1}$. Both estimates of $C_{\mathrm{m}}$ were nearly identical to that predicted from allometry, $0.145 \mathrm{ml} \mathrm{O}_{2} \mathrm{~g}^{-1} \mathrm{~h}^{-1{ }^{\circ}} \mathrm{C}^{-1}$ [25].

Activity patterns were distinctly cyclical in all moles tested. In nearly all cases, persistent $2-4 \mathrm{~h}$ blocks of activity were punctuated by periods of rest lasting 3-5 h (Fig. 3). This activity pattern corresponded closely to the approximate 4-h wake/sleep cycle previously reported for C. cristata and Scalopus aquaticus [1]. Abdominal $T_{\mathrm{b}}$ of the radio-implanted mole averaged $37.5-37.8^{\circ} \mathrm{C}$ over three $24-\mathrm{h}$ periods, with a maximal daily amplitude of $2.2^{\circ} \mathrm{C}$ (range, $36.6-38.8^{\circ} \mathrm{C}$ ). Generally, $T_{\mathrm{b}}$ fluctuated with level of activity, attaining peak values following bursts of motor activity. While the highest $T_{\mathrm{b}} \mathrm{s}$ and most intense periods of activity were recorded during the hours of darkness, no obvious circadian variation in $T_{\mathrm{b}}$ and activity was apparent (Fig. 3).

\section{Discussion}

The star-nosed mole is the only semi-aquatic mole found in the Western Hemisphere, and with the exception of the diminutive shrew-mole (Neurotrichus gibbsii), is the least fossorial of the North American talpids $[3,13]$. Functionally blind, star-nosed moles rely primarily on their specialized and thinly keratinized nasal rays $[4,5]$ to probe the moist surfaces of stream beds, lake bottoms and shallow tunnels for earthworms and aquatic invertebrates [13]. Given this species' epigeal nature, delicate nose, and early divergence [38] from the main talpid line, 30-49 mya [39], it is tempting to speculate that $C$. cristata may have progressed directly from a primitive ancestral cursorial morph to its current semi-aquatic form. Anatomical evidence, however, suggests Condylura passed through a specialized fossorial phase in its evolutionary development [11].

It has long been recognized that burrowing endotherms often exhibit low BMRs, reduced $T_{\mathrm{b}} \mathrm{s}$, and relatively high thermal conductance coefficients, compared to their terrestrial counterparts $[16,20]$. However, at body masses less than ca. $60 \mathrm{~g}$, fossorial mammals tend to have BMRs slightly higher than expected $[6,21]$. Moreover, minimal thermal conductances of small fossorial mammals that are $<1 \mathrm{~kg}$ or inhabit cool burrows $\left(<20^{\circ} \mathrm{C}\right)$ are typically close to those predicted from allometry $[6,21]$. Our results indicate that the basal $\dot{V}_{\mathrm{O}_{2}}$ of star-nosed moles $\left(2.25 \mathrm{ml} \mathrm{O}_{2} \mathrm{~g}^{-1} \mathrm{~h}^{-1}\right)$ is nearly twice the mass-predicted estimate for a comparable-sized eutherian, $1.13 \mathrm{ml} \mathrm{O}_{2} \mathrm{~g}^{-1} \mathrm{~h}^{-1}$ [23]. This basal $\dot{V}_{\mathrm{O}_{2}}$ is also considerably higher than values reported for other moles of comparable size, including the eastern mole, Scalopus aquaticus, $1.41 \mathrm{ml} \mathrm{O}_{2} \mathrm{~g}^{-1} \mathrm{~h}^{-1}$ [21], the broad-footed mole, Scapanus latimanus, $1.25 \mathrm{ml} \mathrm{O}_{2} \mathrm{~g}^{-1}$ $\mathrm{h}^{-1}$ [6], the coast mole, Scapanus orarius $(1.02 \mathrm{ml} \mathrm{O}$ $\mathrm{g}^{-1} \mathrm{~h}^{-1}$, [15], and the larger Townsend's mole, Scapanus townsendii, $0.82 \mathrm{ml} \mathrm{O}_{2} \mathrm{~g}^{-1} \mathrm{~h}^{-1}$ [15]. Starnosed moles also maintain a deep $T_{\mathrm{b}}$ that is ca. 0.6$1.7^{\circ} \mathrm{C}$ higher than those reported, [1,6,21] Campbell unpublished data, for these more evolutionarily derived fossorial talpids [38]. It is noteworthy that the estimated lower critical temperature of star-nosed moles is at least $1.5^{\circ} \mathrm{C}$ lower than for other moles tested to date [6,21]. However, this finding is not surprising, since an elevated BMR should theoretically extend the lower limit of the species' thermoneutral zone [32].

As noted earlier, several aquatic mammalian species appear to be endowed with an intrinsically high BMR $[9,18]$. For example, the sea otter (Enhydra lutris), coypus (Myocastor coypus) and platypus (Ornithorhynchus anatinus) all exhibit BMRs that are substantially greater than those of other closely related members of their respective lineages [7,9,12]. Like $C$. cristata with which it shares a largely sympatric range and semi-aquatic habits, the northern water shrew 
(Sorex palustris) also demonstrates a higher basal $\dot{V}_{\mathrm{O}_{2}}$ (I.W. McIntyre, R.A. MacArthur and K.L. Campbell, unpublished data) than non-aquatic insectivores, Blarina brevicauda [8,24] and N. gibbsii [3], of similar size. The adaptive value of an elevated BMR for semiaquatic existence has been questioned by several investigators [18]. For instance, a chronically elevated BMR dictates a high rate of heat production at all ambient temperatures, and compounds the risk of hyperthermia during activity on land [18,19]. The latter problem would seem especially acute for a semi-aquatic species that is also fossorial, and therefore challenged by the high metabolic heat loads associated with digging [16,35]. Indeed, variation in $T_{\mathrm{b}}$ of the radio-implanted mole appeared to track bursts of motor activity in the soil (Fig. 3).

Direct observations of star-nosed moles engaged in foraging activity indicated that during tunnel excavation, these animals frequently use their noses to probe newly exposed earth in search of prey [5]. Though speculative, it is possible that the relatively large surface area, high vascularity, and remarkably thin $(5-6 \mu \mathrm{m})$ epidermis of the nasal rays [4] afford a proficient heat shunt while foraging in moist soils, thereby retarding the accumulation of excess metabolic heat. However, these same morphological features are also conducive to heat loss during excursions in cold water. Heat loss from the fleshy nose appendages may also account, at least in part, for our finding that minimal thermal conductance is unremarkable in C. cristata, despite the fact that the dense pelage of this species provides an effective waterproof boundary in the aquatic medium, [14] personal observation.

Considering their large surface area-to-volume ratio and the exceptional thermal conductivity of water compared to air, it is not surprising that most small-bodied, semi-aquatic mammals are unable to maintain core $T_{\mathrm{b}}$ while immersed, and tend to cool rapidly in the aquatic medium [18], but see [12,36] for exceptions. Cold acclimation in shrews is accompanied by an elevation of BMR and maximal heat-producing capabilities [8]. Thus, adoption of an elevated BMR, perhaps in conjunction with brown fat thermogenesis, unpublished data [17], may serve to accelerate the rate of rewarming following immersion of star-nosed moles, and may even increase the duration and overall efficiency of foraging bouts. Furthermore, maintenance of an elevated $T_{\mathrm{b}}$ by this species would reduce the risk of immersion hypothermia substantially.

In summary, results of this study reveal that starnosed moles exhibit a high $T_{\mathrm{b}}$, an elevated BMR, a broad thermoneutral zone, but a similar $C_{\mathrm{m}}$, compared to other fossorial talpids examined to date. The observed $C_{\mathrm{m}}$ of $C$. cristata likely reflects a compromise between the need to dissipate excess metabolic heat while surface foraging, and the need to conserve heat during exposure to cold. We suggest that the highly modified nose of this mole provides a major avenue of heat loss in both air and water. Adoption of a relatively high, stable $T_{\mathrm{b}}$ and elevated BMR by this species may augment thermogenesis at sub-thermoneutral air temperatures while lowering risks of hypothermia. These factors, in combination with a reduction in the lower critical temperature, may in part explain the successful invasion of star-nosed moles into more northern regions than those tolerated by other North American talpids. These physiological attributes may also compensate for the high rates of heat loss presumably experienced by these animals during aquatic excursions. Clearly, additional data on the thermoregulatory performance and metabolic responses of these animals in water are required to more accurately delineate this physiological phenotype.

\section{Acknowledgements}

We thank B.D. Jeske and G.A. Fines for their able assistance in trapping and caring for moles in captivity. J.E. Dubois, Manitoba Museum of Man and Nature, kindly furnished lodging quarters and local mole distribution records. B. Joos provided technical assistance with analysis of respiratory measurements, and R. Pierce generously permitted us to live-trap moles on his land. Funding was provided by an NSERC operating grant to R.A.M.; K.L.C. was supported in part by a NSERC Postdoctoral Fellowship.

\section{References}

[1] Allison T, Van Twyver H. Sleep in the moles, Scalopus aquaticus and Condylura cristata. Exp Neurol 1970;27:564-78.

[2] Arieli R. Adaptation of the mammalian gas transport system to subterranean life. In: Nevo E, Reig OA, editors. Evolution of Subterranean Mammals at the Organismal and Molecular Levels. New York: Wiley-Liss, 1989:251-68.

[3] Campbell KL, Hochachka PW. Thermal biology and metabolism of the American shrew-mole, Neurotrichus gibbsii. J Mammal (In press)

[4] Catania KC, Kass JH. The unusual nose and brain of the star-nosed mole. Bioscience 1996;46:578-86.

[5] Catania KC, Kass JH. Somatosensory fovea in the star-nosed mole: behavioral use of the star in relation to innervation patterns and cortical representation. J Comp Neurol 1997;387:215-33.

[6] Contreras LC, McNab BK. Thermoregulation and energetics in subterranean mammals. In: Nevo E, Reig OA Jr., editors. Evolution of Subterranean Mammals at the Organismal and Molecular Levels. New York: Wiley-Liss, 1989:231-50.

[7] Costa DP, Kooyman GL. Oxygen consumption, thermoregulation, and the effect of fur oiling and washing on the sea otter, Enhydra lutris. Can J Zool 1982;60:2761-7.

[8] Dawson TJ, Olsen JM. The summit metabolism of the shorttailed shrew Blarina brevicauda: a high summit is further elevated by cold acclimation. Physiol Zool 1987;60:631-9. 
[9] Doncastor CP, Dumonteil E, Barré H, Jouventin P. Temperature regulation of young coypus (Myocastor coypus) in air and water. Am J Phys 1990;28:1220-7.

[10] Dyck AP, MacArthur RA. Seasonal patterns of body temperature and activity in free-ranging beaver (Castor canadensis). Can J Zool 1992;70:1668-72.

[11] Grand T, Gould E, Montali R. Structure of the proboscis and rays of the star-nosed mole, Condylura cristata. J Mammal 1998;79:492-501.

[12] Grant TR, Dawson TJ. Temperature regulation in the platypus, Ornithorhynchus anatinus: production and loss of metabolic heat in air and water. Physiol Zool 1978;51:315-32.

[13] Hamilton WJ Jr. Habits of the star-nosed mole, Condylura cristata. J Mammal 1931;12:345-55.

[14] Hickman GC. Swimming ability of talpid moles, with particular reference to the semi-aquatic Condylura cristata. Mammalia 1984;48:505-13.

[15] Kenagy GJ, Vleck D. Daily temporal organization of metabolism in small mammals: adaptation and diversity. In: Aschoff J, Daan S, Groos G, editors. Vertebrate Circadian Systems. Berlin: Springer, 1982:322-38.

[16] Lovegrove BG. The cost of burrowing by the social mole rats (Bathyergidae) Cryptomys damarensis and Heterocephalus glaber: The role of soil moisture. Physiol Zool 1989;62:449-69.

[17] MacArthur RA. Brown fat and aquatic temperature regulation in muskrats, Ondatra zibethicus. Physiol Zool 1986;59:306-17.

[18] MacArthur RA. Aquatic mammals in cold. In: Wang LCH, editor. Advances in Comparative and Environmental Physiology, vol. 4. Berlin: Springer, 1989:289-325.

[19] MacArthur RA. Energy metabolism and thermoregulation of beaver (Castor canadensis). Can J Zool 1989;67:651-7.

[20] McNab BK. The metabolism of fossorial rodents: a study of convergence. Ecology 1966;47:712-33.

[21] McNab BK. The influence of body size on the energetics and distribution of fossorial and burrowing mammals. Ecology 1979;60:1010-21.

[22] McNab BK. On estimating thermal conductance in endotherms. Physiol Zool 1980;53:124-56.

[23] McNab BK. Complications inherent in scaling basal rate of metabolism in mammals. Q Rev Biol 1988;63:25-54.
[24] McNab BK. The energy expenditure of shrews. In: Findley JS, Yates TL, editors. The Biology of the Soricidae. Albuquerque, NM: The Museum of Southwestern Biology, University of New Mexico, 1991:35-45.

[25] McNab BK, Morrison PR. Body temperature and metabolism in subspecies of Peromyscus from arid and mesic environments. Ecol Monogr 1963;33:63-82.

[26] Merriam $\mathrm{CH}$. The star-nosed mole amphibious. Science 1884;4:429.

[27] Nickerson DM, Facey DE, Grossman GD. Estimating physiological thresholds with continuous two-phase regression. Physiol Zool 1989;62:866-87.

[28] Pearson OP. The rate of metabolism of some small mammals. Ecology 1947;28:127-45.

[29] Peterson KE, Yates TL. Condylura cristata. Mammal Species 1980;129:1-4.

[30] Rust CC. Notes on the star-nosed mole (Condylura cristata). J Mammal 1966;47:538.

[31] Schmidt FJW. Mammals of western Clark County. J Mammal 1931;12:99-117.

[32] Schmidt-Nielsen K. Animal Physiology: adaptation and environment, 5th edition. Cambridge: Cambridge University Press, 1996.

[33] Seton ET. Life-histories of Northern animals - an account of the mammals of Manitoba, vol. 2. New York: Charles Schribner's Sons, 1909:1136-44.

[34] Sparti A. Comparative temperature regulation of African and European shrews. Comp Biochem Physiol 1990;97A:391-7.

[35] Vleck D. The energy cost of burrowing by the pocket gopher Thomomys bottae. Physiol Zool 1979;52:122-36.

[36] Vogel P. Body temperature and fur quality in swimming watershrews, Neomys fodiens (Mammalia, Insectivora). Z Säugetierkunde 1990;55:73-80.

[37] Weigert G. Nest construction and oxygen consumption of Condylura. J Mammal 1961;42:528-9.

[38] Whidden HP. Comparative myology of moles and the phylogeny of the Talpidae (Mammalia, Lipotyphla). American Museum Novitates (In press)

[39] Yates TL, Greenbaum IF. Biochemical systematics of North American moles (Insectivora: Talpidae). J Mammal 1982;63:368-74. 